\title{
Integration of risk matrix and event tree analysis: a natural stone plant case
}

\author{
M KEMAL ÖZFIRAT ${ }^{1}$, ERKAN ÖZKAN ${ }^{2}$, BAYRAM KAHRAMAN ${ }^{1}$, BAHADIR ŞENGÜN $^{3}$ and \\ MUSTAFA E YETKIN ${ }^{1, *}$ \\ ${ }^{1}$ Department of Mining Engineering, Dokuz Eylul University, 35160 Buca-Izmir, Turkey \\ ${ }^{2}$ Department of Mining Engineering, Afyon Kocatepe University, 03200 Afyonkarahisar, Turkey \\ ${ }^{3}$ Department of Mining Engineering, Cumhuriyet University, 58140 Sivas, Turkey \\ e-mail: kemal.ozfirat@deu.edu.tr; eozkan@aku.edu.tr; bayram.kahraman@deu.edu.tr; \\ mustafa.yetkin@deu.edu.tr
}

MS received 18 August 2016; revised 31 January 2017; accepted 19 February 2017; published online 27 September 2017

\begin{abstract}
Machining has considerably increased with evolving technology and increasing demand in natural stone production facilities. Different types of accidents may occur in natural stone facilities during movement, dimensioning, cutting of blocks and surface processing. These accidents may be due to physical, chemical, ergonomic and mechanical conditions. Therefore, possible work accidents and occupational diseases should be investigated. In this study, an L-matrix analysis is conducted to analyze hazards and forecast risks in natural stone facilities. According to the L-matrix results, three major initiating events are identified. For each of these initiating events, event tree analysis is used to calculate risk scores. These initiating events are hoist rope fatigue and breaking, diamond wire fatigue and breaking, and electrical leakage due to old systems. These events and their results are classified according to the probabilities using event tree analysis.
\end{abstract}

Keywords. Natural stone; risk analysis; L-matrix; event tree analysis.

\section{Introduction}

Risk can be defined as a combination of the probability and severity of accident. A hazard is a potential source of harm or adverse health effect on a person or persons. Risk analysis identifies probable hazards and risks in a work environment and determining the corresponding probabilities and severities. Therefore, risk analysis theory has been used since the 1970s in mining and other industries such as underground mining, tunnels, marble quarries, marble processing plants, automotive plants, space technologies and military operations.

Applying measures of work safety and health is important to protect workers from accidents. To date, risk analysis methods are widely used to evaluate results of work safety and health applications [1-4]. These methods are designed to predict and prevent large-scale accidents. There are numerous risk analysis methods such as preliminary hazard analysis (PHA), L-matrix analysis, event tree analysis (ETA), hazard and operability analysis (HAZOP), fault tree analysis (FTA), bow-tie analysis and fault mode effect analysis [5,6]. Work accidents in the mining sector such as methane blast, water flooding and roof collapse were

*For correspondence catastrophic because of poor and dangerous working conditions in the past. Work accidents often occur as a result of carelessness, lack of education, training and preventive countermeasures. But over the past two decades, the risk of hazards in mining sector has been significantly reduced with newly developed studies in work safety area. Today, as technology evolves, proactive measures are increasingly important and being implemented in work safety science. Proactive measures considerably decrease probability of work accidents. Defining hazards and their probabilities using risk analysis techniques is the first of proactive measures. Given this reason, risk analysis and management must be carried out in mining and other industries.

Work safety and risk analysis in mining has been studied by many researchers. Sanmiquel et al [7] showed the relation between risk index and age, severity and size of the mine. Ozfirat [8] proposed a new risk analysis methodology by incorporating fuzzy techniques into failure mode and effect analysis. The author has applied this methodology for an underground coal mine. Dey et al [9], Onder et al [2], Ozfirat et al [10] and Onder et al [11] have emphasised that major accident risk factors (physical workload, noise, vibration, radiation exposure, diesel exhaust, high temperature and humidity, and exposure to dust and gas-phase hazardous substances) and work groups are high in mines 
and they provided information to decrease work accidents. Szary et al [12] have examined the negative effects of noise, dust and vibration. Hubbard et al [13] and Chan and $\mathrm{Ng}$ [14] have studied the safety signs in mines. Martyka and Lebecki [15] stated that if mining workers adopt work safety culture, risky behaviors would decrease.

In this study, L-matrix analysis, probable risks and preventive measures are carried out in different natural stone factories. Moreover, three major initiating events obtained from L matrix are analyzed and classified according to the ETA.

The significance of the study is that two quantitative risk analysis methods, namely, L-matrix and ETA, are integrated gradually. A complex system is simplified using the L-matrix method. Then, ETA is employed to incorporate detailed precautions in the business plan and to prevent work accidents. The results of the study would enable natural stone producers to preempt clearly the hazards and risks involved in operation workflow. Therefore, the method employed contributes to both the risk analysis literature and the related industry. In addition, the study is different from other risk analysis studies in literature [16-20] since it integrates two different risk analysis methods and provides in-depth analysis of marble industry.

\section{Background}

Mining industry involves many hazards due to the nature of operations. Therefore, work safety rules and regulations must be strictly applied in the mining industry. Literature is abound with studies about physical workload, noise, vibration, high temperature, humidity and exposure to dust and gas-phase hazardous substances. However, studies integrating quantitative risk analysis methods are limited. In this study, a detailed risk analysis is made in marble mining industry. Therefore, the study fills an important gap in terms of hierarchical application of quantitative risk analysis methods.

\subsection{Definition of potential hazards}

This study is carried out in marble plants in the Afyon region. Sources of hazard are grouped as follows:

- Stockyard and piling up the blocks,

- Dimensioning the blocks,

- Carrying the blocks into the plant with cranes,

- Sockets popping out while working with ST block cutter and

- gang saw, and dimensioning,

- Surface grinding-blasting,

- Sanding with the horizontal splitting machine,

- Work conducted in a corrosion chamber and

- Possible hazards from chemical filling.

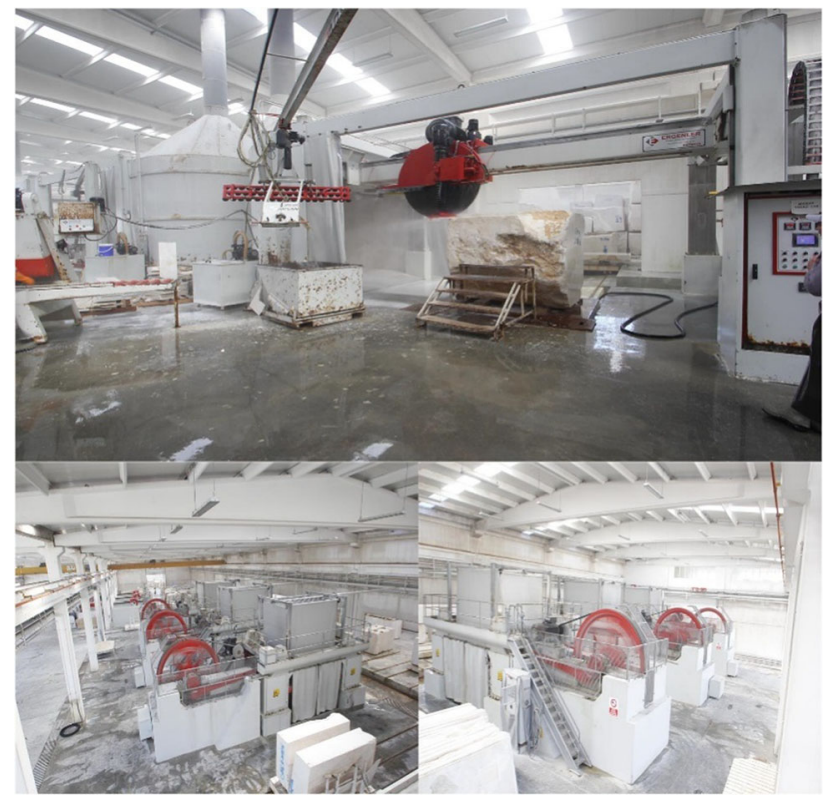

Figure 1. View of the cutting machines in the marble factory.

The activities of a marble processing factory consists of block cutting, block dimensioning, surface abrasive machines, polishing machines and chemicals operations, sandblasting machines, resin filling, restoring machines and transport machines. Therefore, hazards are present in all phases due to working with heavy machinery equipment and heavy natural stones for mining operations in the manufacturing process. Hazards are listed based on occurred accidents, field engineers' and authors' views. Block cutting process is one of the important operations for the end product and these process machines are given in figure 1.

These hazards include bursting of the socket in the circular saw when the cutting speed on the sawing disc (SD) cutter machine is not adjusted according to the type of the natural stone. Another hazard may be bursting of balance wheel on the gang saw machine. In addition, there is the risk of crushing in horizontal splitting machines if the plates fall down. In grinding and polishing, there are possible risks during changing grinds and cleaning plane pieces. In sandblasting there is risk of steel ball bursting. If a wearing plate falls or crashes, the operator's hand may be squeezed. Also, tumbling machines cause high vibration and noise, which may lead to occupational illness. Chemicals may cause allergies, skin burns, and respiratory diseases. In addition, cement and dust in filling may cause work diseases (lung function damage and mesothelioma). In the stocking area, improper stacking of blocks may lead to accidents.

\subsection{Definition of major hazards}

Risk matrix is used to determine major hazards. Risk matrix methods can be classified as L matrix $(3 \times 3)$, L matrix 


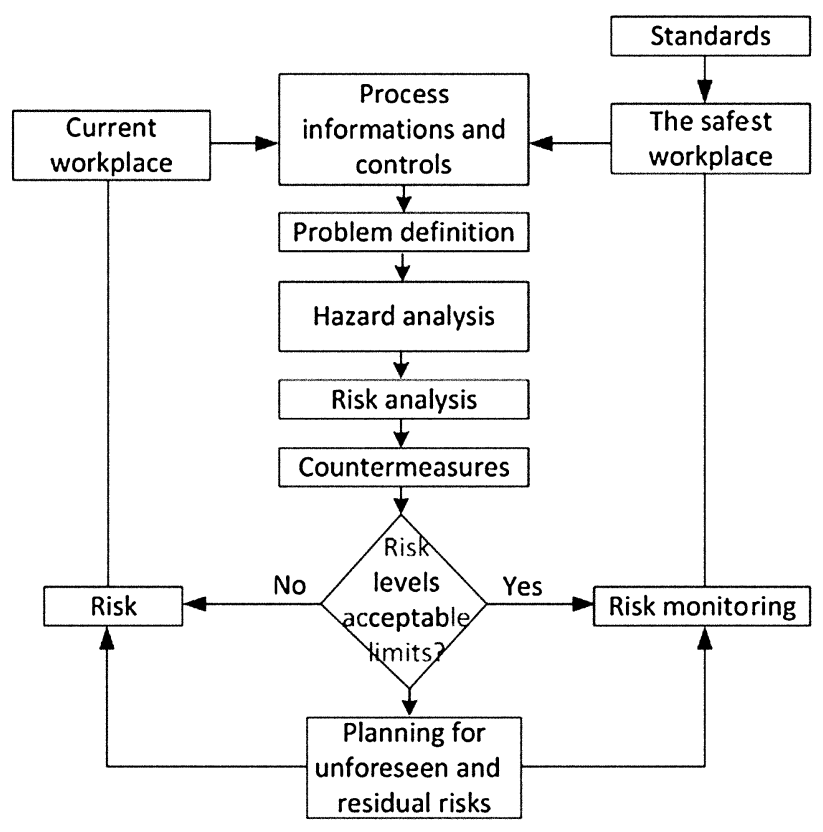

Figure 2. Steps in L-matrix analysis.

$(5 \times 5)$ and $X$ matrix. L matrix $(5 \times 5)$ is a simple method with a useful scale. L matrix $(5 \times 5)$ is a quantitative risk analysis method that leads to in-depth risk analysis. It identifies all potential hazards and events that may lead to an accident, ranks the identified accidental events according to their severity, and identifies the necessary hazard controls and countermeasures [21-31]. For example, it can be used to find out which risks require a detailed analysis, need to be controlled immediately and be brought to the attention of management. In addition, matrix can also be used to find out "negligible" risks. Finally, the matrix can be used to find acceptable/tolerable and unacceptable/intolerable risks [29, 32, 33]. These hazards are separately analyzed and classified, as seen in figure 2.

Risk scores are obtained by multiplying risk severity by probability (Eq. 1).

$$
\text { Risk score }=\text { Probability } \times \text { Severity }
$$

Probability values are evaluated on a scale of five according to their frequency based on plant experts' feedback. The probabilities of accidents caused by falling of blocks, wire wear and electrical fires are less, but they are evaluated as " 3 " in terms of probability and " 5 " in terms of severity by the experts because they may cause serious damages. These accidents are classified as the high-risk group. The risk scores in table 1 are determined using the probability and severity values. Table 1 classifies risks by using a score matrix [28-30].

After calculating the risk scores, risk mitigation and measures are given in table 2 [28, 29]. High risks and

Table 1. Risk score and classification.

\begin{tabular}{|c|c|c|c|c|c|c|c|}
\hline \multirow[b]{2}{*}{ Probability } & \multirow[b]{2}{*}{ Description of probability } & \multirow[b]{2}{*}{$\begin{array}{l}1 \text { time every } \mathrm{x} \\
\text { years }\end{array}$} & \multicolumn{5}{|c|}{ Severity } \\
\hline & & & $\begin{array}{c}(1) \\
\text { Negligible }\end{array}$ & $\begin{array}{c}(2) \\
\text { Marginal }\end{array}$ & $\begin{array}{c}(3) \\
\text { Critical }\end{array}$ & $\begin{array}{c}(4) \\
\text { Serious }\end{array}$ & $\begin{array}{c}(5) \\
\text { Catastrophic }\end{array}$ \\
\hline (1) Very rare & Virtually impossible & $>20$ & 1 & 2 & 3 & 4 & 5 \\
\hline (2) Rare & Unlikely & $3-20$ & 2 & 4 & 6 & 8 & 10 \\
\hline (3) Occasional & $\begin{array}{c}\text { May happen a few times, at } \\
\text { least once }\end{array}$ & $1-3$ & 3 & 6 & 9 & 12 & 15 \\
\hline (4) Probable & May happen several times & $\begin{array}{l}\text { Once every } \\
6 \text { months }\end{array}$ & 4 & 8 & 12 & 16 & 20 \\
\hline (5) Frequent & May happen often & $\begin{array}{l}>\text { Once every } \\
6 \text { months }\end{array}$ & 5 & 10 & 15 & 20 & 25 \\
\hline
\end{tabular}

Risk classification: Low (1-6), Moderate (8-12), High (15-20), Not tolerated (25).

Table 2. Risk score and management.

Result Preventive action

Cannot be tolerated Work should not be started until the risk is reduced. Any ongoing activity must be immediately stopped. If risk

Important risks

$$
\text { (15-20) }
$$

Moderate-level risks (8-12)

Foldable risks (2-6)

Insignificant risk (1)

\section{is not reduced, activity must be immediately stopped}

Work should not be started until the risk is reduced. Any ongoing activity must be immediately stopped. After preventive measures are applied, work can be continued

Risk mitigation measures should be applied. Work can be continued

The risk is low, and further risk reducing measures are not required. However, existing controls should be continued

Existing controls should be continued 
Table 3. Preliminary hazard analysis for natural stone plants.

\begin{tabular}{|c|c|c|c|c|c|c|}
\hline Process & Hazard definition & Effects & Risk mitigation measures & $\mathrm{P}$ & $\mathrm{S}$ & $\mathrm{RS}$ \\
\hline 1 & Fall of blocks & $\begin{array}{c}\text { Injury and } \\
\text { fatal } \\
\text { accident }\end{array}$ & $\begin{array}{c}\text { Placements of blocks in accordance with production planning, } \\
\text { putting chocks between blocks, control of wire rope }\end{array}$ & 3 & 5 & 15 \\
\hline 2 & Wire wear & $\begin{array}{c}\text { Injury and } \\
\text { fatal } \\
\text { accident }\end{array}$ & $\begin{array}{c}\text { Control of cutting speed, accurate adjustment of water quantity, } \\
\text { change of diamond wire }\end{array}$ & 3 & 5 & 15 \\
\hline 3 & Electric fires & $\begin{array}{c}\text { Injury and } \\
\text { fatal } \\
\text { accident }\end{array}$ & $\begin{array}{l}\text { Insulation of main electrical distribution panel, periodic } \\
\text { maintenance and control }\end{array}$ & 3 & 5 & 15 \\
\hline 4 & $\begin{array}{l}\text { Circular saw is breaking off } \\
\text { the saw in cutting }\end{array}$ & $\begin{array}{c}\text { Injury and } \\
\text { fatal } \\
\text { accident }\end{array}$ & $\begin{array}{c}\text { Control of peripheral and cutting speed, accurate adjustment of } \\
\text { water quantity, change of diamond wire }\end{array}$ & 3 & 4 & 12 \\
\hline 5 & $\begin{array}{l}\text { Lack of maintenance of } \\
\text { flywheel }\end{array}$ & $\begin{array}{c}\text { Injury and } \\
\text { fatal } \\
\text { accident }\end{array}$ & $\begin{array}{l}\text { Suitable penetrating speed in cutting marble block, suitable water } \\
\text { quantity }\end{array}$ & 2 & 5 & 10 \\
\hline 6 & $\begin{array}{l}\text { Belt conveyor system open, } \\
\text { tear and break }\end{array}$ & Injury accident & $\begin{array}{c}\text { Mounting the protector to a belt system, being careful while } \\
\text { working, fixing tears and breaks }\end{array}$ & 3 & 3 & 9 \\
\hline 7 & Carrying heavy materials & $\begin{array}{l}\text { Occupational } \\
\text { illness }\end{array}$ & Carrying with mechanic systems & 3 & 2 & 6 \\
\hline 8 & $\begin{array}{l}\text { Chemical materials (epoxy, } \\
\text { etc.) }\end{array}$ & $\begin{array}{l}\text { Occupational } \\
\text { illness }\end{array}$ & Protective equipment & 3 & 2 & 6 \\
\hline
\end{tabular}

$P$ probability, $S$ severity, $R S$ risk score.

important samples from moderate- and low-risk categories are listed in table 3. In this level, the work under "not tolerated" (25) and "high-risk" (15-20) category should not be started until the risk is reduced. If a factory has an ongoing activity, it must be immediately stopped. After preventive measures are taken, work can be continued. In moderate-level risks (8-12), risk mitigation measures should be applied before work can be continued. In "foldable risks" (2-6), the risks are low and further riskreducing measures are not required. However, existing controls should be continued. For insignificant risk (1), existing controls should be continued.

As shown in table 3, the experts and authors give the severity value of " 5 " for all the accidents in high-risk class. Accident results are evaluated either as causalities or as high material damage [28].

\section{Methodology of study}

ETA as a risk evaluation method was first used in the atomic energy field and nuclear power plant operations and was gradually adopted for risk analysis in many other fields and industries such as chemical and mechanical engineering [34]. In ETA method, all possible events in a system are listed on a tree figure. The method is based on computing the probabilities of possible outcomes of an event. The possible outcomes of the event are listed in chronological order on a tree-like diagram. It is different from FTA in terms of using induction logic.
ETA is used for evaluation of major hazards. It is a systematic safety analysis tool that proceeds from the occurrence of an undesired event (accident) to the identification of the root causes of the event [34]. This analysis has been extensively used in risk and safety analyses in many different industries. Five basic steps are used to develop an event tree [5, 34-38]: identifying the initiating event, determining countermeasures, building the event tree, evaluation of the tree, and risk classification.

Many researchers use ETA to evaluate risks [39-42]. In the past, ETA was used to avoid failures in concrete structures and tunnels, as well as to provide safety in drilling systems and drilling regimes [43-45]. In mining, ETA is not frequently used. With evolving technology, mining involves heavy work machinery and equipment. As a result of this trend, many risks and hazards appear in mining administrations. Hence, ETA is applied in mining industry to define risks and undertake proactive measures $[31,46]$.

Building the event tree starts from an initiating event. Depending on whether the next event from the chain occurs or not, the main branch splits into two branches. Each of these splits into two new branches depending on whether the third event occurs or not (i.e. the prevention fails). This process continues until all events from the chain have been considered. For a chain of $n$ events, there will be $2^{n}$ possible final states. The probability of a particular state is equal to the probability of the path leading to this state. This probability is determined as a product of the probabilities of the branches composing the path and the probability or frequency of the initiating event. The probability of the 
undesirable event is the sum of the probabilities of all paths (outcomes) which lead to this event (figure 3). In figure 3, $P_{a i}$ refers to the probability of occurrence of event $a_{i}$ $[34,36]$.

After determined initiating events, these events and their countermeasures are planned. Initiating events are hoist rope fatigue and breaking, diamond wire fatigue and breaking, and electrical leakage caused by old systems. Countermeasures are determined as planning $(\mathrm{P})$ event, machine type and maintenance (MM) event, block control (BC) event, and labor inspection (LI) event.

Planning $(\mathrm{P})$ is important in natural stone factories where a number of processes such as cutting, dimensioning, filling and polishing are carried out. This way, work organisation and material flow between processes become safer. Therefore, good planning decreases work accidents by decreasing the number of unexpected situations (table 4).

Machine type and maintenance (MM) is important in order to select the suitable machine and prevent unexpected machine breakdowns. Unexpected breakdowns lead to a number of accidents since production stops unexpectedly. Therefore, machine should be selected according to block dimensions, and maintenance periods must be followed properly.

Block control (BC) is an important countermeasure to check whether natural stone blocks and machine capacities match each other. In addition, discontinuities on blocks should be controlled. In other ways, major accidents such as block falls and wire rope failures may occur (table 4) [28].

Labor inspection (LI) during work would prompt workers to obey safety rules and regulations, such as use of personal protective equipment. In addition, control of cables in a marble factory would also prevent electrical accidents and fires.

When the countermeasures defined earlier are considered, planning prevents initiating event 1 (hoist rope fatigue and breaking) with $75 \%$ probability, it prevents initiating event 2 (diamond wire fatigue and breaking) with $70 \%$ and prevents initiating event 3 (electrical leakage caused by old systems) with $65 \%$ probability. Machine type and

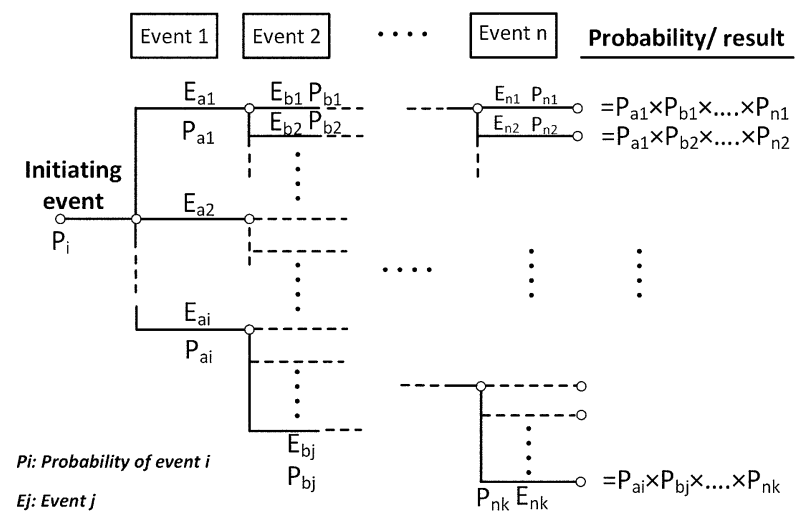

Figure 3. Steps in event tree analysis $[31,34,36]$.
Table 4. Event tree starting events and measures.

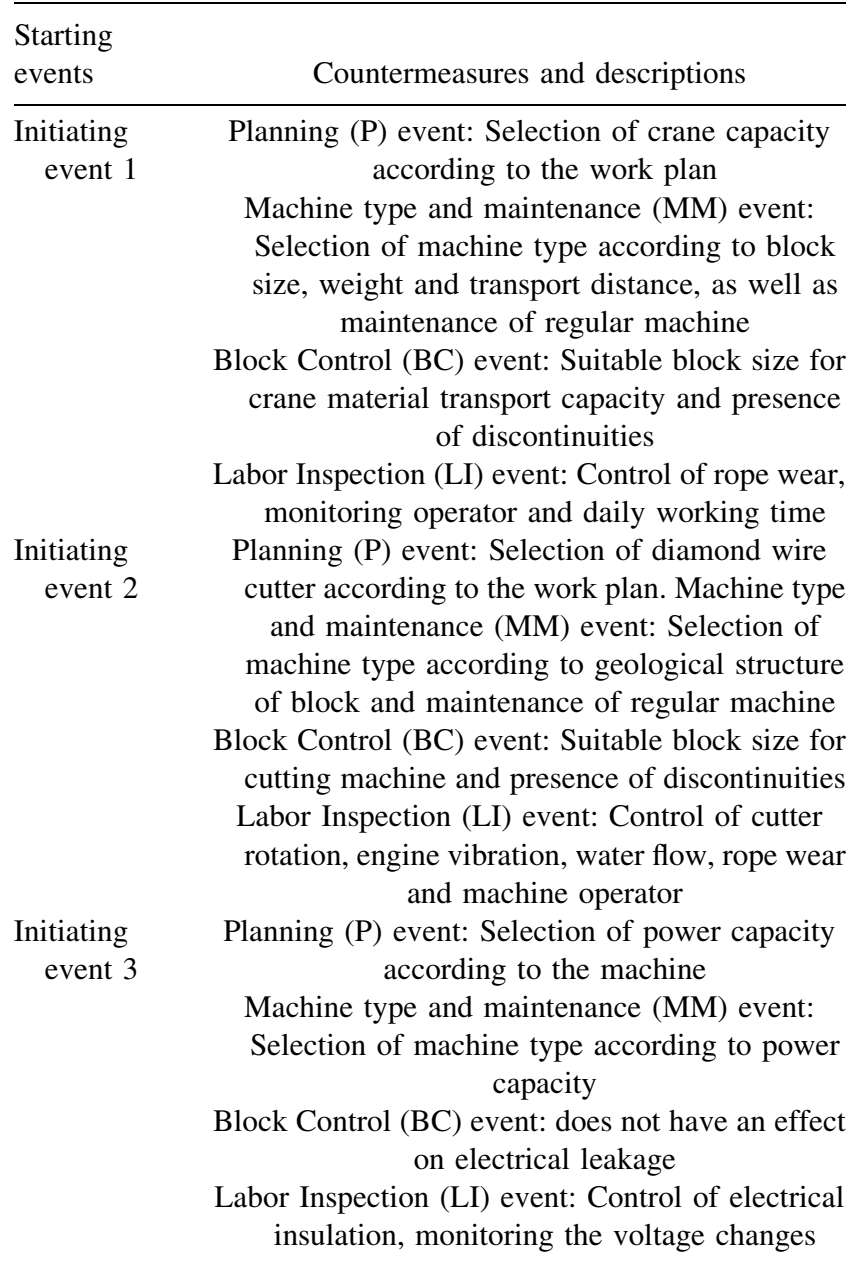

Table 5. Probability of prevention.

\begin{tabular}{lccc}
\hline & $\begin{array}{c}\text { Hoist rope } \\
\text { fatigue and } \\
\text { breaking (\%) }\end{array}$ & $\begin{array}{c}\text { Diamond wire } \\
\text { fatigue and } \\
\text { breaking }(\%)\end{array}$ & $\begin{array}{c}\text { Electrical leakage } \\
\text { due to old systems } \\
(\%)\end{array}$ \\
\hline P & 75 & 70 & 65 \\
MM & 95 & 90 & 95 \\
BC & 85 & 80 & - \\
LI & 95 & 90 & 85 \\
\hline
\end{tabular}

$P$ planning, $M M$ machine type and maintenance, $B C$ block control, $L I$ labor inspection.

maintenance (MM) prevents initiating event 1 with $95 \%$, initiating event 2 with $90 \%$ and initiating event 3 with 95\% probability. Block control prevents initiating events 1 and 2 with $85 \%, 80 \%$ probability, respectively. However, it has no effect on initiating event 3 . Labor inspection is effective on all three initiating events. It prevents initiating events 1 , 2 and 3 with 95,90 and $85 \%$ probabilities, respectively (table 5). 


\section{Performance assessment}

Hoist rope fatigue and breaking (initiating event 1), diamond wire fatigue and breaking (initiating event 2), electrical leakage caused by old systems (initiating event 3 ) events are examined in detail. It can be seen in figures 4-6 subject to the general probability rule $\mathrm{P}_{\text {SUCCESS }}+$ $\mathrm{P}_{\mathrm{FAILURE}}=1$, which means $\mathrm{P}_{\mathrm{YES}}+\mathrm{P}_{\mathrm{NO}}=1$. In hoist rope fatigue and breaking event, "labor inspection" and "machine type and maintenance" both prevent a possible accident with $95 \%$ probability. These two events are very important for initiating event 1 . Therefore, when these two countermeasures are not taken, a possible accident would have a catastrophic result. "Block control" prevents an accident with $85 \%$ probability and "planning" prevents an accident with $75 \%$ probability. Since mining and rock cutting are heavy-duty work, occurrences of the initiating events 1, 2, 3 are assumed to be $1 /$ year. Therefore, probabilities are set as 1 .

Final probabilities are calculated using these values in the event tree given in figure 4 . Then risks are classified as catastrophic, serious, critical, marginal and negligible. In the event tree, each branch is matched with one of these risk groups according to the type of countermeasures taken. In table 6, the probabilities of each risk group is given. According to the table, probability of having a catastrophic accident is 0.00250 and having a negligible accident is 0.67688. As the name refers, if we neglect "negligible" risks, probability of all other risk classifications are

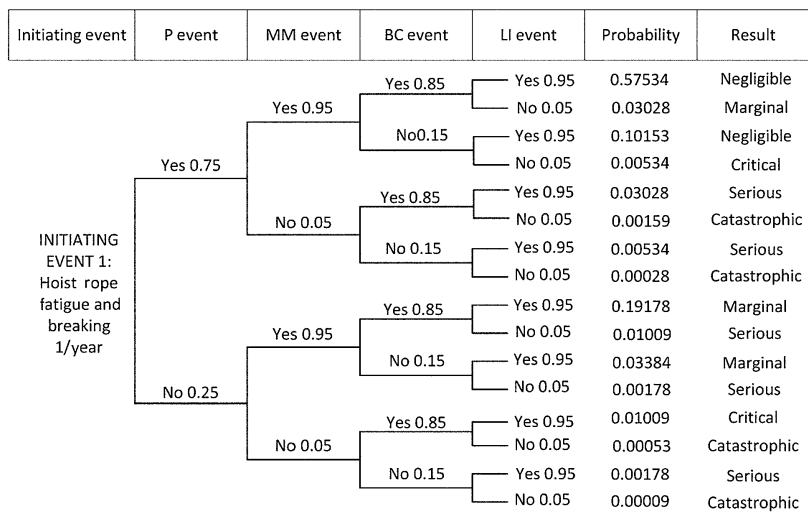

Figure 4. Event tree analysis for hoist rope fatigue and breaking.

Table 6. Probabilities of initiating event 1 .

\begin{tabular}{lc}
\hline Risk class & Probability \\
\hline Catastrophic & 0.00250 \\
Serious & 0.04928 \\
Critical & 0.01543 \\
Marginal & 0.25591 \\
Negligible & 0.67688 \\
Total & 1.00000 \\
\hline
\end{tabular}

$(1-0.67688=0.32312)$. This value refers to the sum of catastrophic, serious, critical and marginal risks. Therefore, it is important to take these countermeasures in order to prevent accidents.

In initiating event 2, diamond wire fatigue and breaking, planning, machine type and maintenance, block control and labor inspection countermeasures prevent an accident with $0.7,0.9,0.8$ and 0.9 probabilities, respectively. Similar to initiating event 1, MM and LI measures are the most effective. When these two countermeasures are missing, the resulting accident would be catastrophic. Event tree is calculated in figure 5 and probabilities of risk classes are given in table 7 . Table 7 shows that the probability of having a catastrophic accident is 0.0100 . The total probability of all risk classes except for negligible risk is 0.4536 (figure 5).

In electrical leakage due to old systems event (initiating event 3), only three countermeasures are effective. These are P, MM and LI. The prevention probabilities of these three countermeasures are $0.65,0.95$ and 0.85 , respectively. Block control has no effect on electrical leakage. Therefore, it is not considered in the event tree given in figure 6. Risk classifications and the corresponding probabilities are given in table 8 . It can be seen in the table that probability of a catastrophic accident is 0.0075 . In addition, the total probability of accidents other than negligible is 0.52488 .

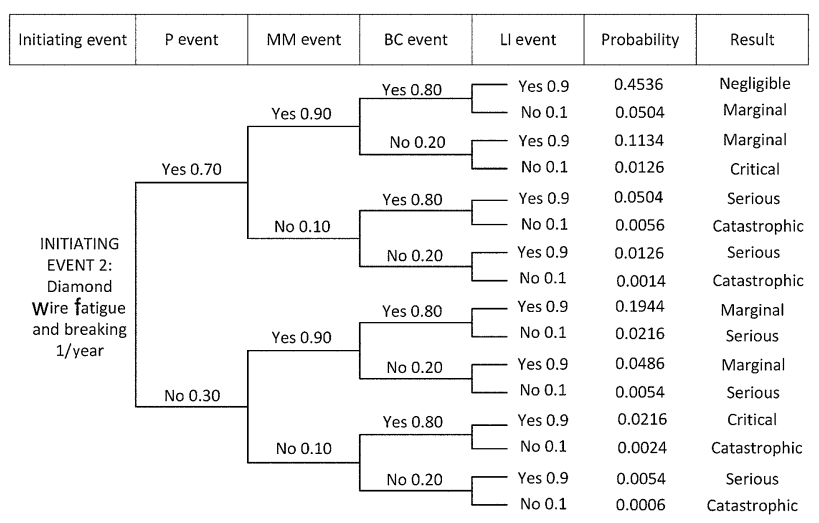

Figure 5. Event tree analysis for diamond wire fatigue and breaking.

Table 7. Probabilities of initiating event 2.

\begin{tabular}{lc}
\hline Risk class & Probability \\
\hline Catastrophic & 0.0100 \\
Serious & 0.0954 \\
Critical & 0.0342 \\
Marginal & 0.4068 \\
Negligible & 0.4536 \\
Total & 1.0000 \\
\hline
\end{tabular}




\section{Discussion and evaluation}

In the study, possible risks in natural stone operation plants are identified by the authors. Hoist rope fatigue, diamond wire fatigue and electrical leakage due to old system are selected to be the initiating events using L-matrix method. After determining the initiating events, prevention methods on these events are analyzed in detail using ETA. Possible faults in the system and their probabilities are determined. General hierarchy of the method is given in figure 7 .

The two main barriers to preventing hoist rope fatigue hazard from turning into an accident are machine maintenance and labor inspection. This is because we can prevent breaking of hoist rope with machine maintenance and labor inspection. Ropes must be checked before use; safety coefficients must be 5; they must be chosen according to the type of the load; and they must be oiled and must not be exposed to heat in welding operations. If the load has sharp corners, necessary precautions must be taken. In addition, lifting equipment must be checked by the operator before every use and by an authorised personnel every three months. Dynamic experiments must be carried out with a load of 1.5 times the maximum load. The most important precautions for diamond wire fatigue are also MM and LI. In case the diamond wire breaks, an operator must be behind a sheet. Finally, electrical leakage must prevented because much water is used in the marble cutting process. Therefore, inspection, machine maintenance and changing worn-out cables are vital.

Andrews and Dunnett [16] considered the binary decision diagrams, which constitute the basis of ETA. However,

\begin{tabular}{|c|c|c|c|c|c|}
\hline Initiating event & P event & MM event & Ll event & Probability & Result \\
\hline \multirow{8}{*}{$\begin{array}{l}\text { INITIATING } \\
\text { EVENT 3: } \\
\text { Electrical } \\
\text { leakage due } \\
\text { to old } \\
\text { systems } \\
1 / \text { year }\end{array}$} & & Yes 0.95 & - Yes 0.85 & 0.52488 & Negligible \\
\hline & Yes 0.65 & \multirow[b]{2}{*}{ No 0.05} & \multirow{2}{*}{ - Nos 0.15} & 0.09262 & Critical \\
\hline & \multirow{5}{*}{ No 0.35} & & & 0.02762 & Serious \\
\hline & & & - No 0.15 & 0.00488 & Catastrophic \\
\hline & & Yes 0.95 & -Yes 0.85 & 0.28262 & Marginal \\
\hline & & \multirow{3}{*}{ No 0.05} & - No 0.15 & 0.04988 & Critical \\
\hline & & & — Yes 0.85 & 0.01488 & Serious \\
\hline & & & - No 0.15 & 0.00262 & Catastrophic \\
\hline
\end{tabular}

Figure 6. Event tree analysis for electric leakage caused by old systems.

Table 8. Probabilities of initiating event 3.

\begin{tabular}{lc}
\hline Risk class & Probability \\
\hline Catastrophic & 0.00750 \\
Serious & 0.04250 \\
Critical & 0.14250 \\
Marginal & 0.28262 \\
Negligible & 0.52488 \\
Total & 1.00000 \\
\hline
\end{tabular}

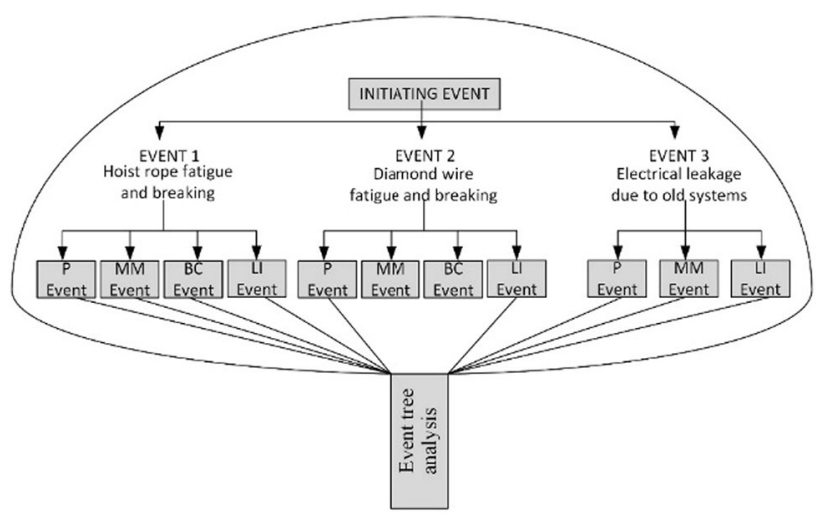

Figure 7. System hierarchy of event tree analysis.

they have not presented a field study. Einstein [3], Mizrak Ozfirat [8], Onder et al [11], Kasaeyan et al [19], Xue et al [20], Bhattacharja [37] and Aghajani [38] consider risk classification using different risk analysis methods. However, in this study, in-depth initiating event analysis is made using ETA. In addition, ETA was previously employed in tunneling studies in order to analyze initiating events by Hong et al [27], Pamukcu [31] and Beard [44]. Peila and Guardini [17] employed FTA to provide safe operation of machinery preventing rock block falls. There are some other studies supporting this study, which employs different methods. These methods are similar to our study in terms of integrating an alternative method to ETA. However, Sun et al [18] integrate Human Cognitive Reliability (HCR) and ETA to decrease risk degrees in aviation industry. Alileche et al [39] considered domino effect in FTA for the process industry. Karanki et al [40] and Karanki and Dang [41] studied dynamic event trees and accident sequence models. Lower et al [42] modified ETA according to fuzzy rules and classified traffic accidents using the proposed methodology. However, to the best of our knowledge, this is the first study that applies ETA in marble mining and processing. The model developed shows and classifies the outcomes and their probabilities in case of neglecting any of the precautions determined. Risks are analyzed in detail considering the basic parameters. Therefore, this study is important for mining industry in which heavy-duty machines bring up many risks in all phases of production.

\section{Conclusion}

Risk analysis is used in all industries in the recent years according to the developing safety science. Risk analysis defines hazards, determines countermeasures and prevents work accidents. In this study, L-matrix and ETA are applied in natural stone factories using L-matrix analysis, three initiating events are found. Hoist rope fatigue and breaking, diamond wire fatigue and breaking and electrical leakage caused by old systems turned out to be the initiating events. The 
countermeasures for each of these three events are determined. Event tree is built, and risks are classified according to severity. Finally, probabilities of each risk class are calculated. Catastrophic accident probabilities are calculated as 0.0025 , 0.01 , and 0.0075 for hoist rope fatigue and breaking, diamond wire fatigue and breaking, electrical leakage events, respectively.

\section{References}

[1] Sari M, Selcuk A S, Karpuz C and Duzgun H S B 2009 Stochastic modeling of accident risks associated with an underground coal mine in Turkey. Saf. Sci. 47: 78-87

[2] Onder M, Onder S, Akdag T and Ozgun F 2009 Investigation of dust levels in different areas of underground coal mines. Int. J. Occup. Saf. Ergon. 15: 125-130

[3] Einstein H H 1996 Risk and risk analysis in rock engineering. Tunnel. Undergr. Space Technol. 2: 141-155

[4] Ciarapica F E and Giacchetta G 2009 Classification and prediction of occupational injury risk using soft computing techniques. Saf. Sci. 47: 36-49

[5] Bahr N J 1997 System safety engineering and risk assessment. A practical approach. Washington: Taylor \& Francis

[6] Zhang M, Kecojevic V and Komljenovic D 2014 Investigation of haul truck-related fatal accidents in surface mining using event tree analysis. Saf. Sci. 65: 106-117

[7] Sanmiquel L, Freijo M and Rossell J 2012 Exploratory analysis of Spanish energetic mining accidents. Int. J. Occup. Saf. Ergon. 18: 209-219

[8] Mizrak Ozfirat P 2014 A new risk analysis methodology integrating fuzzy prioritization method and failure modes and effects analysis. J. Fac. Eng. Archit. Gazi Univ. 29: 755-768 (in Turkish)

[9] Dey N C, Samanta A and Saha R 2006 A study of the workload of underground trammers in the Ranigang coal field area of West Bengal, India. Int. J. Occup. Saf. Ergon. 12: 399-407

[10] Özfırat M K, Mizrak Özfırat P, Kahraman B, Can Y and Öney Ö 2013 Classification of underground mine accidents sourced by transportation risks using fault mode effect analysis. In: Work Health and Safety in Mines Symposium, Adana, Turkey, pp. 289-295 (in Turkish)

[11] Onder M, Onder S and Adiguzel E 2014 Applying hierarchical loglinear models to nonfatal underground coal mine accidents for safety management. Int. J. Occup. Saf. Ergon. 20: 239-248

[12] Szary M L, Chugh Y P and Hirschi J 2011 Noise variability in underground room and pillar coal mines. Int. J. Occup. Saf. Ergon. 17: 301-308

[13] Hubbard C, Naqvi S A and Capra M 2001 Heavy mining vehicle controls \& skidding accidents. Int. J. Occup. Saf. Ergon. 7: 211-221

[14] Chan A H S and Ng A W Y 2012 The guessing of mine safety signs meaning: effects of user factors and cognitive sign features. Int. J. Occup. Saf. Ergon. 18: 195-208

[15] Martyka J and Lebecki K 2014 Safety culture in high-risk industries. Int. J. Occup. Saf. Ergon. 20: 561-572

[16] Andrews J D and Dunnett S J 2000 Event-tree analysis using binary decision diagrams. IEEE Trans. Reliab. 49: 230-239
[17] Peila D and Guardini C 2008 Use of the event tree to assess the risk reduction obtained from rock fall protection devices. Natl. Hazards Earth Syst. Sci. 8: 1441-1450

[18] Sun R, Chen Y, Liu X, Peng T and Liu L 2011 A method of analysis integrating HCR and ETA modeling for determining risks associated with inadequate flight separation events. $J$. Aviat. Technol. Eng. 1: 19-27

[19] Kasaeyan M, Wang J, Jenkinson I and Lavasani M R 2011 Fuzzy consequence modelling of hydrocarbon offshore pipeline. Int. J. Mar. Sci. Eng. 1: 3-12

[20] Xue L, Fan J, Rausand M and Zhang L 2013 A safety barrierbased accident model for offshore drilling blowouts. Loss Prevent. Process Ind. 26: 164-171

[21] Coburn A and Spence R 1992 Earthquake protection. London: Wiley

[22] Morgan M G 1993 Risk analysis and management. Science 1: $18-23$

[23] Brehmer B 1994 The psychology of risk. In: Singleton W $\mathrm{T}$ and Hovden $\mathrm{J}$ (eds) Risk and decisions. West Sussex: Wiley

[24] Niczyporuk Z T 1996 Safety management in coal mines-risk assessment. Int. J. Occup. Saf. Ergon. 2: 243-250

[25] Andrews J and Moss B 2002 Reliability and risk assessment. 2nd ed. London: Wiley

[26] Okuyama S E and Chang E 2004 Modeling spatial economic impacts of disasters. Berlin: Springer

[27] Hong E S, Lee I M, Shin H S, Nam S W and Kong J S 2009 Quantitative risk evaluation based on event tree analysis technique: application to the design of shield TBM. Tunnel. Undergr. Space Technol. 24: 269-277

[28] Ozfirat M K, Ozkan E, Kahraman B, Sengun E and Yetkin M E 2012 Risk analysis and management in natural stone plants. In: 8th International Marble and Natural Stone Congress (in Turkish)

[29] Ozkilic O 2014 Risk assessment. p 426. Ankara: TISK

[30] Bevilacqua M, Ciarapica F E and Giacchetta G 2008 Industrial and occupational ergonomics in the petrochemical process industry: a regression trees approach. Accid. Anal. Prevent. 40: 1468-1479

[31] Pamukcu C 2015 Analysis and management of risks experienced in tunnel construction. Acta Montan. Slovaca 20(4): 271-281

[32] Rausand M and Hoyland A 2004 System reliability theory: models, statistical methods, and applications. 2nd ed. USA: Wiley

[33] Moseman J 2011 New risk acceptance criteria for process safety. Process Saf. Progress 31: 6-8

[34] Clemens P L 1990 Event tree analysis. 2nd ed. Tullahoma, USA: Sverdrup Technology Inc

[35] Stapelberg R F 2009 Handbook of reliability, availability, maintainability and safety in engineering design. London: Springer

[36] Ang A H S and Tang W H 1984 Probability concepts in engineering planning and design. pp. 498-504. New York: Wiley

[37] Bhattacharya B, Lu Q and Zhong J 2009 Reliability of redundant ductile structures with uncertain system failure criteria. Sadhana 34(6): 903-921

[38] Aghajani H F, Salehzadeh H and Shahnazari H 2015 Stability analysis of sandy slope considering anisotropy effect in friction angle. Sadhana 40(6): 1955-1974 
[39] Alileche N, Olivier D, Estel L and Cozzani V 2016 Analysis of domino effect in the process industry using the event tree method. Saf. Sci. 97: 10-19

[40] Karanki D R, Kim T W and Dang V N 2015 A dynamic event tree informed approach to probabilistic accident sequence modeling: dynamics and variabilities in medium LOCA. Reliab. Eng. Syst. Saf. 142: 78-91

[41] Karanki D R and Dang V N 2016 Quantification of dynamic event trees-a comparison with event trees for MLOCA scenario. Reliab. Eng. Syst. Saf. 147: 19-31

[42] Lower M, Magott J and Skorupski J 2016 Analysis of air traffic incidents using event trees with fuzzy probabilities. Fuzzy Sets Syst. 293: 50-79
[43] Hadipriono F C, Lim C L and Wong K H 1986 Event tree analysis to prevent failures in temporary structures. J. Constr. Eng. Manag. 112: 500-513

[44] Beard A N 2010 Tunnel safety, risk assessment and decisionmaking. Tunnel. Undergr. Space Technol. 25: 91-94

[45] Rosqvist T, Molarius R, Virta H and Perrels A 2013 Event tree analysis for flood protection-an exploratory study in Finland. Reliab. Eng. Syst. Saf. 112: 1-7

[46] Ramzali N, Lavasani M R M and Ghodousi J 2015 Safety barriers analysis of offshore drilling system by employing fuzzy event tree analysis. Saf. Sci. 78: 49-59 